
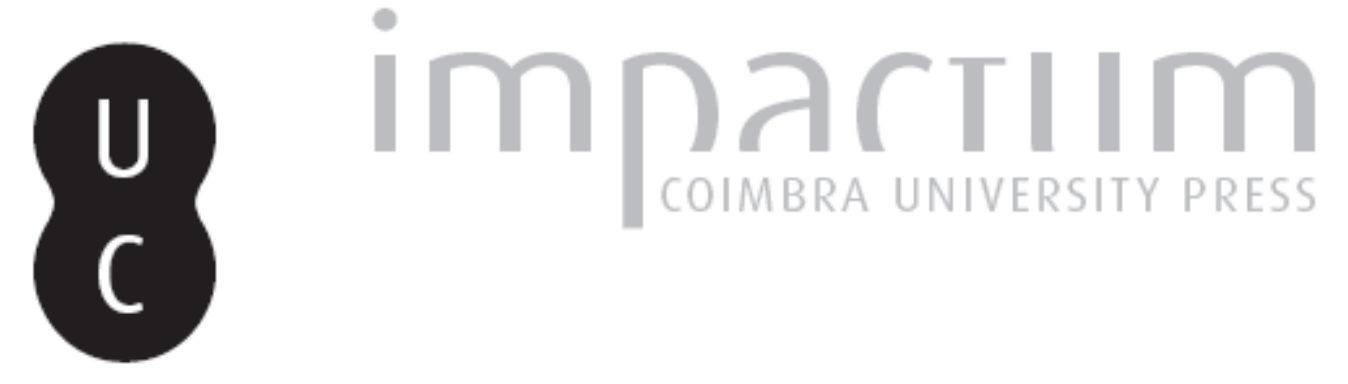

\title{
Os caminhos da paleopatologia: passado e desafios
}

\section{Autor(es): $\quad$ Santos, Ana Luísa}

Publicado por: CIAS - Centro de Investigação em Antropologia e Saúde

URL persistente:

URI:http://hdl.handle.net/10316.2/41246

DOI:

DOI:http://dx.doi.org/10.14195/2182-7982_17_10

Accessed : $\quad$ 26-Apr-2023 15:55:56

A navegação consulta e descarregamento dos títulos inseridos nas Bibliotecas Digitais UC Digitalis, UC Pombalina e UC Impactum, pressupõem a aceitação plena e sem reservas dos Termos e Condições de Uso destas Bibliotecas Digitais, disponíveis em https://digitalis.uc.pt/pt-pt/termos.

Conforme exposto nos referidos Termos e Condições de Uso, o descarregamento de títulos de acesso restrito requer uma licença válida de autorização devendo o utilizador aceder ao(s) documento(s) a partir de um endereço de IP da instituição detentora da supramencionada licença.

Ao utilizador é apenas permitido o descarregamento para uso pessoal, pelo que o emprego do(s) título(s) descarregado(s) para outro fim, designadamente comercial, carece de autorização do respetivo autor ou editor da obra.

Na medida em que todas as obras da UC Digitalis se encontram protegidas pelo Código do Direito de Autor e Direitos Conexos e demais legislação aplicável, toda a cópia, parcial ou total, deste documento, nos casos em que é legalmente admitida, deverá conter ou fazer-se acompanhar por este aviso.

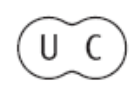




\section{Antropologia Portuguesa}

$16-17 \cdot 1999-2000$

Departamento de Antropologia | Universidade de Coimbra 


\title{
Os caminhos da paleopatologia - passado e desafios
}

\author{
Ana Luísa Santos \\ Departamento de Antropologia \\ Universidade de Coimbra \\ 3000-056 Coimbra, PORTUGAL \\ alsantos@ci.uc.pt
}

\section{Resumo}

O percurso da paleopatologia desde o seu alvorear até à actualidade, onde se segue uma abordagem biocultural e se aplicam meios técnicos sofisticados, é revisto neste trabalho. Em complemento ao desenvolvimento geral da disciplina, também é retratado o seu progresso em Portugal. Em última análise, salienta-se a importância da paleopatologia que, para além de permitir um conhecimento mais aprofundado dos contextos socioculturais e demográficos das populações do passado, se perspectiva como um precioso auxiliar nas estratégias de prevenção da saúde pública, constituindo uma das suas possíveis aplicações.

\section{Palavras-chave}

Paleopatologia, abordagem biocultural, Portugal, metodologias, história da ciência

\section{Abstract}

This article traces the history of paleopathology as a discipline from its early beginnings to the present days, when a biocultural approach is employed and sophisticated technical methods are applied. The development of this discipline within Portugal is also reviewed, as a counterpart to the general overview. In the last analysis, the importance of paleopathology is emphasized not only for its contributions to our understanding of the sociocultural and demographic contexts of health in the past populations, but also as a valuable auxiliary in modern public heath programs aimed at disease prevention.

\section{Key words}

Paleopathology, biocultural approach, Portugal, methodologies, history of science 


\section{Nota de apresentação}

A decisão de escrever um texto em língua portuguesa sobre paleopatologia e a sua história pretende inserir-se na contribuição para a aparente dialéctica entre o grande desenvolvimento da disciplina em Portugal e a carência de trabalhos em português sobre os seus avanços, em geral. Por seu turno, a inclusão duma secção sobre a paleopatologia portuguesa, pretende, mais do que reunir os dados apurados, incentivar a troca e a compilação de documentos dispersos para que os desenvolvimentos sejam registados e se preencham lacunas e/ou omissões, eventualmente detectadas, ao longo deste texto.

A origem e a evolução da paleopatologia está documentada por muitos trabalhos em diversas línguas, particularmente a inglesa, o que dificulta a escolha, nomeadamente como bibliografia de referência, para estudantes que optem por se iniciar neste tema. Provavelmente a única compilação em português resulta da tradução do texto de Buikstra e Cook (1980), efectuada aquando da publicação, coordenada por Araújo e Ferreira (1992), resultante do $1^{\circ}$ Curso de Especialização em Paleopatologia e Paleoepidemiologia, realizado no Rio de Janeiro, em 1991. Apesar do seu grande interesse, reconhece-se, no entanto, a dificuldade de acesso e a diminuta propagação desta obra em Portugal. Não obstante a vintena de anos passados sobre a edição do original de Buikstra e Cook, o seu conteúdo científico não perdeu a actualidade e recomenda-se a sua leitura.

O propósito de difundir a paleopatologia, divulgando a sua abrangência, e simultanamente fornecer fontes bibliográficas que permitem aprofundar a temática, encontra-se entre as preocupações justificativas do artigo que aqui se apresenta.

\section{Introduçāo à Paleopatologia}

Etimologicamente, a palavra paleopatologia designa o estudo (logos) do sofrimento ou doença (páthos) antigo (paleo), sendo a sua criação associada ao ano de 1910 e atribuída a Sir Marc Armand Ruffer (1858-1917)'.

\footnotetext{
' Os dados biográficos de alguns investigadores foram obtidos em Spencer (1997)
} 
Na realidade esta filiação resulta de um equívoco, já que este médico desempenhou um papel importante na sua divulgaçāo, visto o neologismo ter surgido num título de R. W. Schufeldt publicado em 1893 (Waldron, 1994; Cockburn, 2000).

Não obstante, a sua antiguidade, esta disciplina permanece relativamente desconhecida, facto agravado pela ausência do vocábulo revelada pela pesquisa realizada em diversos dicionários de Português. A sua inserção no Oxford English Dictionary, significando "o estudo das condições patológicas encontradas em seres humanos e animais do passado" data, somente, de 1987 (Cockburn, 1997). Todavia, esta definiçāo, bastante concisa, não esclarece completamente a abrangência da disciplina. Uma das limitações mais comuns é a ênfase dada à paleopatologia humana. Indubitavelmente a articulação entre esta ciência e a fitopaleopatologia e a zoopaleopatologia, nomeadamente em animais domésticos, deverá ser um objectivo a alcançar, genericamente pela disciplina já que, até ao presente, os estudos propenderam mais para universos separados. Assim, multiplicam-se as precisões e os debates em torno de uma definição. A proposta mais englobante, e que ao mesmo tempo tem o mérito de obviar pleonasmos, designa-a como a "ciência que estuda a doença no passado, através do exame e interpretacão dos restos biológicos e de outras fontes" [Documento elaborado por M. Campo Martín na sequência do forum em rede da Asociación Española de Paleopatología].

No que diz respeito à paleopatologia humana, actualmente é considerada uma subdisciplina da Antropologia Biológica (Buikstra e Ubelaker, 1994; Roberts e Manchester, 1995) dedicada ao estudo da evolução e progresso das doenças, em seres humanos e noutros animais, através dos tempos (Roberts e Manchester, 1995; Miller et al., 1996; Concise Colour Medical Dictionary, 1998), examinando diversas fontes de informaçāo. Assim, o paleopatologista investiga evidências primárias, tais como os ossos, os tecidos calcificados, corpos preservados, múmias e os coprólitos, e evidências secundárias no leque das quais se incluem a documentação contemporânea dos materiais em análise (registos médicos e históricos) e as representações iconográficas, artefactos e obras de arte (Ortner e Putschar, 1981; Roberts e Manchester, 1995; Armelagos, 1997). A paleopatologia é particularmente importante em contextos pré-históricos para os quais não existem documentos escritos sobre saúde ou sobre a prática médica (Lovell, 2000). 
O estudo da história das doenças pretende assim uma "abordagem biocultural", com os dados biológicos a serem interpretados no seu contexto cultural, o qual inclui detalhes relevantes sobre o desenvolvimento histórico, a geografia do local e a cultura material dos povos cujos restos estão a ser examinados (Manchester, 1983; Roberts e Manchester, 1995) representando, assim, a recente vocaçāo transdisciplinar da paleopatologia. Desde a década de 1950, a colaboração entre antropólogos físicos e paleopatologistas, promoveu esta perspectiva que frutificou em estudos realizados nos anos de 1970 e 80 sobretudo em materiais da América do Norte e do Sul (Armelagos, 1997) e do Mediterrâneo (Buikstra e Cook, 1992).

Nos últimos 20 anos, a paleopatologia teve um impacto importante noutras ciências (Armelagos, 1997). O estudo da mortalidade e da morbilidade de populações pretéritas é essencial para a avaliação da susceptibilidade a determinadas doenças e desordens (Pfeiffer, 1991) e, também, contribui para o conhecimento médico actual, designadamente dos meios de diagnóstico (Møller-Christensen, 1953; 1967 in Ortner e Putschar, 1981; Rogers et al., 1990) aplicáveis, ainda, nas ciências forenses. A integração de dados demográficos e de morbilidade com outros aspectos da cultura e da medicina tornam a moderna paleopatologia uma ciência verdadeiramente holística (Santos, 2000).

\section{O percurso da disciplina}

O estado actual da investigação paleopatológica resulta de um percurso bicentenário analisado sob várias perspectivas por diferentes autores como sejam, a título de exemplo, Buikstra e Cook (1980), Ortner e Putschar (1981), Ubelaker (1982), Armelagos (1997), Aufderheide e Rodríguez-Martín (1998) e, mais recentemente, Lovell (2000). Estes trabalhos diferem essencialmente nas denominações e respectivos limites cronológicos. Devido ao carácter do presente artigo, apresenta-se uma súmula das ideias e dos acontecimentos considerados determinantes ou tidos como importantes no progresso da disciplina.

A emergência da paleopatologia foi marcada por alguns equívocos tendo acontecido mesmo que fósseis de animais fossem confundidos com casos patológicos em seres humanos. Exemplos destas situaçōes foram os trabalhos do anatomista F. Plater (1536-1614), que identificou fósseis de 
elefante como se de ossos de gigante humano se tratassem, e do naturalista Scheuchzer que, em 1726, confundiu ossos de salamandra com os de vítimas do dilúvio descrito no Genesis (Aufderheide e Rodríguez-Martín, 1998). Após estes precalços iniciais, em 1774, J. F. Esper (1742-1810) registou um osteosarcoma no fémur de um urso das cavernas, diagnóstico refutado por Mayer em 1854 que o considerou uma simples fractura (Waldron, 1994). Os ossos de animais fossilizados foram a matéria dos relatórios escritos entre o século XVIII e inícios do século XIX, sendo exemplificativa a descrição de patologias em especímenes paleontológicos efectuada pelo anatomista G. Cuvier (1769-1832) em 1820 (Ortner e Putschar, 1981; Armelagos, 1997; Cockburn, 1997). Mas, cinco anos depois, iniciam-se autópsias em múmias (Armelagos, 1997).

As primeiras publicações resultaram, assim, de casos isolados e dos respectivos diagnósticos. Exceptuam-se, no panorama meramente descritivo, os estudos de H. Allen (1841-1897), médico e professor na Universidade de Filadélfia (Armelagos, 1997).

Durante o século XIX surgiram estudos que constituiram marcos na paleopatologia humana: R. Virchow (1821-1902), patologista alemão, analisou um esqueleto patológico de Neandertal da Gruta de Feldhofen (Aufderheide e Rodríguez-Martín, 1998), o médico checo J. N. Czermak (1828-1873) identificou, em 1879, através de exame histológico arteriosclerose numa artéria de uma múmia egípcia (Armelagos, 1997; Aufderheide e Rodríguez-Martín, 1998), J. C. Warren (1778-1856), professor de anatomia e cirurgia, e S. G. Morton descreveram deformações cranianas respectivamente em 1822 e 1839 e J. Jones (1833-1896), em 1876, apresentou uma monografia, com o primeiro estudo de doenças em seres humanos do passado, onde identifica a sífilis na América do Norte (Waldron, 1994). Segundo Campillo (1993), Pierre-Paul Broca identificou uma trepanação num crânio Peruano, anterior à chegada de Colombo.

Os estudos decorridos nas últimas décadas do século XIX e nas primeiras do século XX são considerados como a fase de consolidação da disciplina, designada por Buikstra e Cook (1980) como o "período analítico" enquanto Armelagos (1997) refere-a como "período formativo" por ser caracterizado por dois temas emergentes: a determinação da história e geografia de doenças específicas e a aplicação dos avanços técnicos da medicina. Veja-se, por exemplo, que bastaram dois anos sobre a descober- 
ta dos raios-x para que o egiptólogo inglês W. F. Petrie (1853-1942) empregasse esta técnica no estudo das múmias.

Entre outros investigadores desta fase salientam-se os autores de extensos estudos de múmias e esqueletos egípcios: M. A. Ruffer, R. L. Moodie (1880-1934, EUA), G. Elliot Smith (1871-1937, nascido na Austrália) e F. Wood Jones (1879-1954) anatomista de origem britânica (Ortner e Putschar, 1981; Ortner, 1991; Roberts e Manchester, 1995; Cockburn, 1997; Aufderheide e Rodríguez-Martín, 1998). Para o apogeu da descoberta e divulgação das múmias também contribuiram Max Uhle, Julio Tello, José Imbelloni (1885-1967)², Aleš Hrdli-ka (1869-1943) ${ }^{3}$, R. L. Moodie e H. U. Williams que efectuaram estudos em esqueletos das Américas (Allison e Gerszten, 1997; Cockburn, 1997; Aufderheide e Rodríguez-Martín, 1998).

Em França, L. Pales (1930 in Waldron, 1994) publica Paléopathologie et pathologie comparative um dos textos clássicos ao lado dos livros de Moodie e de Ruffer.

Ao invés de casos isolados, a perspectiva epidemiológica da paleopatologia, ou seja, baseada na análise populacional teve como marco definitivo os trabalhos de Earnest A. Hooton (1887-1954, nascido nos EUA) publicados em 1925 e 1930 , sobre os restos de habitantes aborígenes das Ilhas Canárias (Ortner e Putschar, 1981; Roberts e Manchester, 1995; Armelagos, 1997).

\section{O passado próximo}

A era moderna da paleopatologia começa para Armelagos (1997) na década de 1960. Os anos 1960/1970 podem ser considerados como o período áureo da paleopatologia. Até então a situação comum era a selecção de esqueletos com óbvios sinais de doença pelo arqueólogo que os entregava ao médico para que redigisse um relatório, perfeitamente periférico, a incluir no seu trabalho. Ainda em finais dos anos 50 ocorreu uma trans-

\footnotetext{
"Italiano, ligado às ciências naturais e à antropologia que viveu grande parte da sua vida na Argentina

' Nascido na Boémia, actual República Checa, estabeleceu-se nos EUA onde estudou medicina e fundou em 1918 a revista American Joumal of Physical Anthropology
} 
formação importante: a antropologia física e a paleopatologia deixaram de ser consideradas como ramos da medicina (Jarcho, 1966 in Waldron, 1994). Iniciou-se, assim, o período da paleopatologia onde o elemento interpretativo é dominante e que teve como um dos mais notáveis proponentes Calvin Wells (1908-1978), médico inglês (Waldron, 1994).

O desenvolvimento das técnicas de diagnóstico e de modelos paleoepidemiológicos para regiões geográficas específicas e o aparecimento de projectos interdisciplinares produziram avanços tremendos na disciplina (Buikstra e Cook, 1980; 1992; Aufderheide e Rodríguez-Martín, 1998), como é disso exemplo o grupo brasileiro liderado pelo médico Luiz Fernando Ferreira, um dos precursores da paleoparasitologia (Ferreira, Araújo e Confaloniere, 1988). Concomitantemente, são publicadas várias obras de referência que volvido o século continuam a ser das mais requisitadas da biblioteca do/pelo paleopatologista. Salientam-se Ossos, corpos e doenças (1964) de C. Wells", "Diseases in Antiquity" (1967) editado por Don Brothwell e A. T. Sandison [Springfield, Illinois, Charles C. Thomas], "Paleopathological Diagnosis and Interpretation: Bone Diseases in Ancient Human Populations" de R. T. Steinbock (1976) e "Human Paleopathology" editada em 1966 [London, Yale University Press] por Saul Jarcho (1906-2000).

Em língua portuguesa é de salientar o importante contributo da Fundação Oswaldo Cruz (FIOCRUZ), no Rio de Janeiro, (http://www. fiocruz.br/) cujos investigadores têm participado ao longo das últimas décadas em diversas actividades científicas (Araújo e Ferreira, 1992) e de divulgação (Lessa e Souza, 2001).

O primeiro simpósio de paleopatologia humana que decorreu em Washington D.C., e que levou a um importante desenvolvimento desta disciplina, foi organizado em 1965 por Jarcho e teve as respectivas actas publicadas no ano seguinte (Armelagos, 1997; Cockburn, 1997). Outro acontecimento significativo no decurso da paleopatologia foi a criação, em 1973, pelo médico de Saúde Pública T. Aidan Cockburn (1912-1981) e por colegas seus do Canadá e dos EUA, do Paleopathology Club em

+ A versāo portuguesa publicada pela Editorial Verbo saíu no mesmo ano do lançamento em Inglaterra de Bomes, Bodies and Disease 
Detroit (Michigan, EUA), mais tarde rebaptizado para Paleopathology Association $^{5}$ (Cockburn, 1994; Armelagos, 1997; Aufderheide e Rodríguez-Martín, 1998). Esta associaçāo edita, desde 1973, a Paleopathology Newsletter (Buikstra e Cook, 1992). Actualmente, este boletim trimestral é enviado a mais de 600 membros que representam a disciplina em 45 países de cinco continentes, "still no members in Antarctica" como afirma Powell (2000:1) no balanço recentemente efectuado. A PPA também promove um congresso anual nos EUA ( $29^{\mathrm{a}}$ edição em 2002) e, desde 1976, um bienal na Europa, com o $14^{\circ}$, em 2002, a ter como anfitrião o Departamento de Antropologia da Faculdade de Ciências e Tecnologia da Universidade de Coimbra ${ }^{6}$.

Em 1978, Marvin J. Allison e Enrique Gerszten, médicos/patologistas no Medical College of Virginia (Richmond, EUA), fundaram uma outra organização, o Paleopathology Club (Allison e Gerszten, 1997). Desde então foram promovidos encontros em diferentes cidades dos EUA e do Canadá, tendo-se realizado o $90^{\circ}$ Meeting em 2001. O Club envia, trimestralmente, aos cerca de 600 membros, o Paleopathology Newsletter que inclui um slide de um caso para identificação/discussão (Allison e Gerszten, 1997) e é também responsável pelo site http://views.vcu. edu/ pat/paleopathology.

Outros países formaram as suas próprias associaçōes profissionais dedicadas à paleopatologia. Em Espanha o primeiro Laboratório foi criado em 1971 no Museu de Arqueologia de Barcelona (Campillo, 1993) e em 1987 foi constituída a "Asociacion Española de Paleopatologia". Um ano mais tarde decorreu a primeira "Reunión" e em 1991 o "Congreso Nacional de Paleopatología" que continua até à actualidade ( $6^{a}$ edição, Madrid, 2001). Esta Associação endereça aos seus membros o "Boletín de la Asociación Española de Paleopatología", quatro números por ano, com informações diversas e compilaçōes de referências bibliográficas, fomenta também viagens por locais de interesse arqueológico e osteo-

3 Actualmente, conhecida pela abreviatura PPA (http://www.paleopathology.org/), encontra-se informalmente associada à American Association of Physical Anthropology (Buikstra e Cook, 1992). A PPA instituiu em 2000 o "Anmual Cockburn Student Award" cujo designação homenageia o casal Aidan e Eve Cockburn.

'Site oficial http://emppa2002.uc.pt 
lógico em Espanha e em Portugal e mantém, desde 1997, um grupo de discussão em paleopatologia [paleopat@listerserv.rediris.es], bem como o site em http://www.ucm.es.info/aep/ onde se podem obter informações relativas à organização de cursos de paleopatologia e de antropologia forense.

Os cursos são importantes formas de aprofundar conhecimentos e esclarecer dúvidas, tanto de principiantes como para os já iniciados na ciência, e são diversas as instituições que os promovem. As Universidades de Bradford e Durham (no Reino Unido) e a Smithsonian Institution (Washington, D.C., EUA) ministram conjuntamente o "Paleopathology Short Course" com forte articulação das componentes teórica e prática. Em 2001 a Universidade de Copenhaga (Dinamarca) realizou um curso breve e no corrente ano decorrerá na Universidade de Gottingen (Alemanha) um curso prático sobre a microestrutura óssea e as suas aplicações no diagnóstico paleopatológico (Schultz, 2001).

$\mathrm{Na}$ Europa, existem ainda duas outras organizaçōes de paleopatologia, o "Groupe des Paléopathologistes de Langue Française" e a "Società Italiana de Paleopatología" responsável pelo "Bollettino della Società Italiana di Paleopatologia" e uma na América do Sul, a "Asociación Colombiana de Paleopatología".

No que concerne à divulgação dos estudos de paleopatologia, em todo o mundo as publicações começaram em revistas médicas e de anatomia, de antropologia física/biológica e de arqueologia o que, aliás, ainda hoje acontece com o objectivo de abranger outros públicos e fomentar estudos multi/interdisciplinares. Contudo, o aumento do número dos profissionais e a ampliação das especificidades gerou a necessidade de uma publicação temática concretizada em Itália em 1987 com o Joumal of Paleopathology (três números/ano). Quatro anos depois saiu o primeiro volume da revista inglesa Intemational Joumal of Osteoarchaeology (trimestral), ainda que aborde outros temas, abrange particularmente a paleopatologia.

\section{Desenvolvimentos Portugueses}

Tal como noutros países, em Portugal, aparentemente, os estudos de vestígios humanos antigos foram conduzidos inicialmente por médicos e geólogos, como é o caso de muitos dos participantes no "IXme Congrès International d'Anthropologie et Archeólogie Préhistoriques" que decor- 
reu em Lisboa no ano de 1880 (Compte rendu de la neuvième session du Congrès International d'Anthropologie et d'Archéologie préhistorique, 1884).

Quanto à paleopatologia, as primeiras publicações registaram alteraçōes na coluna vertebral, nomeadamente fusão atlanto-occipital, em colecções anatómicas dos séculos XIX e XX mas também em material arqueológico (Sueiro, 1926; Monteiro e Tavares, 1928). Aliás a variação do ráquis é objecto de vários trabalhos de Barbosa Sueiro (1894-1974), médico e professor em Lisboa. Entre os seus estudos, frequentemente representativos de variações morfológicas, salienta-se uma publicação acerca de um sacro mesolítico de Cabeço da Arruda (Sueiro, 1932) entre outros materiais pré-históricos (Sueiro, 1931; 1933/1934). Este mesmo autor efectuou também uma análise do buraco oleocraniano e da apófise supra-epitroclear, na qual observou mais de 2.000 úmeros humanos, de vários períodos históricos e pré-históricos, e mais de uma centena de esqueletos de mamíferos (Sueiro, 1923; 1924/25; 1931). Posteriormente, Salvador Júnior (1947) descreveu lesões patológicas de origem neoplásica e traumática em crânios neolíticos de Eira Pedrinha (Condeixa, Coimbra) e Sueiro e Frazão (1957/9) estudaram a patologia dentária em materiais mesolíticos.

Nesta época foram descritos e diagnosticados alguns casos patológicos enquanto outros foram excluídos de estudos morfológicos, tal era o objectivo da época tanto em Portugal como noutras escolas da Europa e das Américas. $O$ retrato desta situação está bem patente na seguinte frase: "Foi excluído o esqueleto designado por VIb, em virtude de se tratar manifestamente dum indivíduo anormal: os fémures sāo exageradamente encurvados, e o crânio apresenta uma espessura de carácter patológico" (Serra et al., 1952:204) acerca de um esqueleto exumado em Silveirona (Estremoz, Alto Alentejo) e atribuído ao período Visigótico (Cunha e Neto,1953; 1955). Uma reanálise efectuada cerca de 40 anos depois revelou que este esqueleto terá pertencido a um homem com doença de Paget (Lopes, 1997; Lopes e Cunha, 2000).

Nas décadas seguintes, foram publicados por médicos como Armando Santinho Cunha, Caria Mendes e José Carlos Oliveira (Mendes e Oliveira, 1990), por Teles Antunes e pelo arqueólogo Ferreira (1983; 1995) diversos trabalhos sobre casos patológicos.

Idealmente a análise paleopatológica deveria começar durante a exumação ou escavação dos restos humanos ou de animais pois, frequente- 
mente, as lesões patológicas fragilizam o tecido ósseo tornando-o evanescente. Este estado é agravado após a descoberta, pela subsequente deterioraçāo aquando da remoçāo do solo que o abrigou durante décadas, séculos ou milénios. Outro aspecto que nāo deve ser descurado é o registo da envolvente cultural dos restos osteológicos em estudo de modo a inferir como determinadas patologias eventualmente influenciaram, por exemplo, o curso da vida do núcleo sociocultural. Como consequência destes factores, apesar de enunciados de modo sumário, torna-se evidente a pertinência do trabalho de colaboração entre antropólogos, arqueólogos e demais profissionais desde momentos tāo precoces como o planeamento da intervenção de campo. A conclusão do estudo laboratorial, e ocorrências mais tardias tais como, a musealização do local ou a exposição do espólio, para não mencionar aspectos óbvios de coordenação na apresentação de dados, devem também beneficiar e ser fruto desta aliança.

Em Portugal uma presença mais sistemática de um especialista em antropologia na escavação de esqueletos humanos começou em $1986 \mathrm{com}$ Teresa Fernandes [actualmente docente da Universidade de Évora] na intervenção coordenada pelo [extinto] Serviço Regional de Arqueologia do Sul, do IPPC, no Mosteiro da Flor da Rosa (Crato, Alto Alentejo) em parceria com a equipa de arqueologia coordenada por Rui Parreira. A primeira publicação resultante desta articulação foi assinada por Manuela Abelho (1990) ao descrever, de forma muito breve, ocorrências patológicas em individuos Medievais exumados da Igreja de S. Manços (Distrito de Évora). Ainda em material equevo, Eugénia Cunha (1994) efectuou uma análise paleodemográfica e paleopatológica sistemática em indivíduos recuperados da Igreja de S. João de Almedina (Coimbra) e de Fão (Esposende, Braga). Para tempos mais recuados, foram estudados dentes humanos provenientes da Gruta da Lapa do Suão por Maria Augusta Rocha (1978) e das Grutas Artificiais do Tojal de Vila Chã (Carenque, Estremadura) por Cidália Duarte (1993).

Entre as cooperações internacionais salientam-se três equipas que têm participado em escavações e análises laboratoriais em Portugal. No Baixo Alentejo, o Campo Arqueológico de Mértola reúne investigadores portugueses e espanhóis de diferentes áreas como a antropologia física, cujos trabalhos em curso integram estudos paleopatológicos em indivíduos exumados de necrópoles paleocristãs. No Alto Alentejo, Torre de Palma apresenta na sua estratigrafia passagens romanas a medievais, 
integrando investigadores dos EUA e onde ocorrem também estudos paleopatológicos (www.louisville.edu/ aoclar01 /torredp/Torre_dp.htm, 2001). Em vários sítios arqueológicos portugueses, um grupo canadiano dedica-se essencialmente à análise da transição entre as comunidades de caçadores-recolectores e as de agricultores (Lubell et al., 1994).

$\mathrm{Na}$ última década as escavações com restos osteológicos humanos associados têm beneficiado do grande desenvolvimento desta área no Departamento de Antropologia, da Faculdade de Ciências e Tecnologia da Universidade de Coimbra, no Instituto Português de Arqueologia (IPA) e no Instituto Português do Património Arquitectónico e Arqueológico (IPPAR) que acompanharam e acompanham vários trabalhos por todo o território. Da intervenção do IPA destaca-se a escavação e estudo do esqueleto de criança do Abrigo do Lagar Velho, datada do Paleolítico Superior (Duarte et al. 1999).

Em 1999 foi constituida a BioAnthropos, empresa sediada no Instituto Pedro Nunes em Coimbra, a exercer estudos nesta área, e em Lisboa surgiu o CIPA (Centro de Investigaçāo em Paleoecologia Humana) que nas suas atribuições também incluem estudos de paleopatologia.

Como se pode depreender, os técnicos e investigadores em paleopatologia associam-se a estudos paleodemográficos e de antropologia funerária. A importância desta actividade foi reconhecida e regulamentada em 19997. Visivelmente o cenário mudou nos últimos anos e, desde entāo, muitos artigos foram publicados em revistas portuguesas e estrangeiras e teses académicas foram concluídas. A revista Antropologia Portuguesa tem coligido cronologicamente essas referências na secção "Informação bibliográfica". Acresce a estes títulos algumas dezenas de relatórios técnico-científicos [não publicados] elaborados por diversos investigadores e estudantes de Antropologia Biológica onde também são estudados casos patológicos.

7 "A escavação de necrópoles onde se presume venha a ser encontrado espólio antropológico só será autorizada caso a equipa promotora tenha garantida a colaboraçāo de especialistas em antropologia física." (Diário da Repriblica, I-A série, de 15 de Julho de 1999, Decreto-lei no 270/99, Art. $\left.8^{\circ}: 4414\right)$ ). 


\section{Os métodos e as técnicas}

O conhecimento da origem e evolução das doenças pode beneficiar com o estudo de seres humanos antigos quando consideradas as suas patologias (Buikstra e Ubelaker, 1994). Esta temática reúne profissonais de diversas disciplinas tais como a antropologia, história, medicina, literatura entre muitos outros. Esta pluridisciplinaridade deve-se não só à importância e fascínio causado por esta ciência, mas também porque não há campo do conhecimento que seja completamente abrangente (Ubelaker, 1998). No entanto, esta ciência tem tanto de excitante como de frustante pois, se por um lado são manuseados vestígios de vidas pretéritas, por outro, a informação obtida é bastante inferior à desejada quer por antropológos ou por arqueológos (Rogers e Waldron, 1995).

Nos últimos anos, muitos trabalhos centraram-se nos aspectos clíni$\cos$ das doenças, todavia a identificação em restos esqueléticos é muito mais complexa e, portanto, muitas vezes rodeada de controvérsia, particularmente em casos que afectam os tecidos moles, a maioria diga-se, ou naqueles que provocam uma morte rápida. Outro aspecto, digno de realce é a uniformidade das reacções do tecido ósseo a diversas doenças, as quais, são por vezes impeditivas que as impressões deixadas sejam patognómicas. Para além destas razões existem outras que influenciam a qualidade e quantidade do registo, como o fraco estado de preservação de alguns materiais e a perícia do observador.

Depreende-se assim que os diagnósticos, embora questionáveis, são mais fidedignos dependendo do conhecimento das características ou do padrão das lesões associado a determinada patologia mas, também, dos meios utilizados. Até $c a$. de 1970 o diagnóstico era conseguido por abordagem clínica a qual corresponde a critérios pouco definidos e discutíveis (Buikstra e Cook, 1992). Actualmente, procura-se fazer um diagnóstico diferencial, ou seja analisar todos os diagnósticos possíveis perante as evidências existentes procurando-se, em seguida, descartar as ocorrências menos plausíveis até se chegar ao(s) diagnóstico(s) mais provável(eis). A utilização desta metodologia em muito beneficia das colecções de material identificado, nas quais a causa de morte se encontra registada, pois permite aferir até que ponto os critérios de diagnóstico sāo adequados (Santos, 2000). Afortunamente, em Portugal foram constituídas várias, sendo a primeira a colecção de crânios F. Ferraz de 
Macedo (1845-1907) organizada, entre 1875 e 1877, no Museu Bocage, em Lisboa (Olivier e Almeida, 1972; Rocha, 1995). Infelizmente quase todo o material foi destruído aquando do incêndio que deflagrou em 1978 na Faculdade de Ciências de Lisboa.

Em Coimbra, Bernardino Machado (1851-1944)" foi responsável pela formação da Colecção de Crânios "Escolas Médicas" (Tamagnini e Serra, 1942; Tamagnini, 1947; Cunha, 1982; Areia e Rocha, 1985, Areia et al., 1991; Rocha, 1995). O seu sucessor, depois de 1907, Eusébio Tamagnini (1880-1972) durante a direcção da Seç̧ão de Antropologia do Museu de História Natural, constitui a Colecção de Crânios "Trocas Internacionais" e a Colecção de Esqueletos Identificados (Rocha, 1995; Santos, 2000). Esta última com o maior número de estudos paleopatológicos efectuados, em áreas como doença hiperostótica e hipoplasias (Cunha, 1993; Cunha, 1995), linhas de Harris (Cunha e Gomes, 1994), entesopatias (Cunha e Umbelino, 1995), tuberculose (Santos, 2000; Santos e Roberts, 2001) e um caso de mieloma (Santos e Cunha, 2001).

No Porto, A. Mendes Corrêa (1888-1959) ${ }^{10}$ formou uma colecçāo identificada mas, também aqui, o fogo destruiu alguns especímenes e identificações.

Recentemente, Luís Lopes" e Teresa Fernandes começaram, respectivamente no Museu Bocage e na Universidade de Évora, novas colecções identificadas que irão seguramente dar um importante contributo ao estudo da paleopatologia.

Outro aspecto importante num estudo desta natureza é a criteriosa selecção da bibliografia, nomeadamente a de cariz médico. No entanto, existem aspectos observados durante o exame paleopatológico que não correspondem aos perfis verificados na prática clínica (Santos, 2000).

"médico e professor, discípulo de Broca

"professor da Faculdade de Filosofia Natural e criador da disciplina de "Anthropologia, Paleontologia Humana e Archeologia Préhistórica"

"'médico e professor que estabeleceu a cadeira de antropologia em 1912. Em 1930) organiza o Mtemacional Congress of Anthropology and Prehistory Archeology (Lubell $\mathrm{e}$ Jackes, 1997) $(2000)$

"Dados demográficos sobre esta Colecção podem ser encontrados em Cardoso 
Apesar destes entraves, a maioria das pesquisas começa com o exame macroscópico durante o qual se efectua uma descrição cuidada e detalhada do tipo de lesões e da sua localização, de modo a permitir uma avaliação independente da patologia e do seu comportamento através dos tempos (Ortner, 1991). Esta descrição é ainda importante na comparação de dados entre investigadores e em casos de materiais sujeitos a "re-enterramento" ou repatriamento. Consequência desta exigência legal, e com o objectivo de colmatar eventuais deficiências no registo e de sistematizar a informação recolhida, foi desenvolvido algum software como, por exemplo, o descrito por Ortner (1991) e os "Standards" de Buikstra e Ubelaker (1994), o qual pode ser adaptado às exigências de cada estudo em particular. Em alternativa pode ser criada por cada investigador uma base de dados usufruindo de programas comerciais como o Dbase, Excel ou Access.

$\mathrm{O}$ registo da imagem em suporte fotográfico e/ou digital é essencial na publicação e divulgação científicas como, também, para fins didácticos e como instrumento perene de informação. Deveria ser prática corrente, a conservação de uma cópia desse material numa instituição diferente daquela que detém o espólio, precavendo assim perdas maiores resultantes de imprevistos, como incêndios ou fenómenos naturais.

Dependendo do tempo e dos recursos disponíveis, outros métodos de análise podem ser empregues. A radiologia serve a paleopatologia desde o momento da sua descoberta (Cockburn, 1997) com a grande vantagem de ser uma técnica conservativa. Mais recentemente as suas variantes, tomografia computorizada e a versão trimendisional desta, são aplicadas para conseguir um maior pormenor das estruturas internas, o que constitui uma mais valia nos estudos, pese embora o custo mais oneroso.

O paleopatologista deve utilizar todas as ferramentas ao seu dispôr e agregar novas técnicas ou aparelhos. Esta flexibilidade está retratada na própria história da disciplina, por exemplo, o microscópio foi aplicado inicialmente por Louis Agassiz (1822-1843) no estudo de microestruturas dentárias fossilizadas (Aufderheide e Rodríguez-Martín, 1998) e continua a ser usado em estudos histológicos, tanto na versão clássica como na variante electrónica (Wakely et al., 1989; Schultz, 1999).

Durante séculos os procedimentos metodológicos cingiram-se à pesquisa das marcas existentes no hospedeiro. Recentemente, ocorreu uma viragem, a investigaçāo foca-se na prospecção do agente patogénico. Estas novas ferramentas destrutivas analisam biomoléculas e isótopos 
preservados em ossos, dentes e tecidos moles. Após tentativas iniciais de extraç̧ão e clonagem de A.D.N. por Higuchi e colaboradores (1984) surge a técnica "polymerase chain reaction" (PCR) que usa "primers" e A.D.N. polimerases, enzimas termoestáveis (Mullis e Faloona, 1987 in Baron et al., 1996). Em teoria, em poucas horas esta técnica amplifica mais de um milhão de fragmentos de A.D.N. de 50 a 2000, ou mais, pares de bases (Spigelman e Lemma, 1993).

A adaptação do PCR ao estudo do A.D.N. antigo tornou viável o estudo de especímenes do passado. Assim, o cérebro humano com mais de 7.500 anos foi analisado com sucesso por Pääbo e colaboradores (1988). A partir de então foram introduzidos aperfeiçoamentos e consequentemente deu-se a adaptação desta técnica de diagnóstico clínico para o estudo de paleopatologias. A título de exemplo, em 1993, Spigelman e Lemma identificam A.D.N. do complexo Mycobacterium tuberculosis em ossos, Salo e colaboradores (1994) obtiveram idênticos resultados usando amostra de pulmāo de múmia peruana e, posteriormente foram pesquisadas doenças como a lepra (Rafi et al., 1994) e a peste (Drancourt et al., 1998).

Também os lípidos das paredes celulares de organismos do complexo M. tuberculosis (Gernaey et al., 1998; 1999; Santos, 2000) e M. leprae podem ser pesquisados por HPLC ("high-performance liquid chromatography"). Mais uma vez a paleopatologia apropriou-se da investigação médica e farmacêutica para reconstruir o passado.

\section{Trilhos para o futuro}

O conhecimento acumulado ao longo de mais de 200 anos e a anexação das mais recentes metodologias pela paleopatologia ainda não produziu os frutos ambicionados em 1968 por Sandison quando enumerou os maiores problemas desta disciplina transformando-os em desafios para o futuro:

o estabelecimento de um registo de casos a nível mundial, sugestão também advogada por Manchester (1983);

- a criação de uma base bibliográfica central;

- a identificação de material esquelético com história de vida conhecidas;

. a acumulação de casos ilustrativos de situações "clássicas". 
O primeiro dos quatro pontos, tal como Roberts e Manchester (1995) referiram, é a área que tem recebido mais atenção. Relativamente aos últimos dois itens, apesar de alguns estudos em colecções anatómicas de museus e de escolas médicas ainda persistem vários hiatos. Quanto à segunda sugestão, surgiram trabalhos sectoriais com Eckert (1970), Armelagos e colaboradores (1971) e Crain (1971), citados por Tyson (1997). O Paleopathology Nerisletter, desde 1977, com Michael R. Zimmerman como primeiro editor, também inclui em cada número uma secção designada "Annotated bibliography" com publicações consideradas relevantes para a disciplina. Estes acções, apesar da sua extrema importância, foram parcelares, não tendo colmatado as necessidades de aglutinação da informação aliadas a uma pesquisa rápida. Assim, em 1987, o San Diego Museum of Man abraça uma tarefa monumental, e por isso demorada, de recolha e informatização bibliográfica que dez anos volvidos originou de Human Paleopathology and Related Subjects. An International Bibliography (Elerick, 1997). Esta compilação, com mais de 26.000 entradas, foi comercializada em forma de livro acompanhado das respectivas disquetes. A actualização desta informação através de suplementos estava prevista desde o início, surgindo a primeira já em 2001, desta feita em $C D$ com diferentes versões, nomeadamente compatíveis com os sistemas PC e Macintosh. Sem sombra de dúvida, é uma ferramental suberba tanto para investigadores como para estudantes de paleopatologia.

O percurso parece estar delineado, porém, e apesar da diversificação dos meios, as palavras de T. Sandison (1968:238 in Merbs, 1997) continuam a servir de mote para reflexão acerca do perfil dos paleopatologistas "a good scholar who has proceeded to a degree in anthropology; graduated in medicine, spent some time as a resident in general and orthopaedic surgery, been trained as a general pathologist and radiologist and who thereafter specialized in the pathology of bones and joints. He must be imbued with a love for the past, but have a capacity for acquiring and using the techniques of the future". No entanto, os tempos mudaram e C. Merbs (1997:xix) comentou-a do seguinte modo: "Today one might add that the "degree in anthropology" should be a Ph. D., that the second sentence begin he or she, and that "love for the past" be combined with a great knowledge and understanding of the past". Resta-nos a questão: quem pretende, ou acredita, ser perfeito? A solução, provavel- 
mente, encontra-se na contínua investigaçāo, se possível transdisciplinar, adaptada a novos desafios de modo a que a paleopatologia não só responda ao desejo de conhecer o passado da humanidade como seja uma aliada na prevenção e tratamento de futuras epidemias/pandemias e de fenómenos esporádicos, consequência de adaptações a novos ambientes.

\section{Bibliografia}

Abelho, M. 1990. Estudo antropológico dos enterramentos de S. Manços (Évora). Antropologia Portuguesa, 8: 69-100.

Allison, M.; Gerszten, E. 1997. The tradition of international research. The South American example. In: Elerick, D. (compil.). Human Paleopathology and Related Subjects. An Intemational Bibliography: San Diego, San Diego Museum of Man: xvii-xviii.

Araújo, A.; Ferreira, L. 1992 (ed.) Paleopatologia. Paleoepidemiologia. Estudos multidisciplinares. Rio de Janeiro, Escola Nacional de Saúde Pública, Fundaçāo Oswaldo Cruz Panorama.

Araújo, A.; Ferreira, L.; Confalonieri, U. 1988. Paleoparasitologia no Brasil. Rio de Janeiro, Escola Nacional de Saúde Pública/Programa de Educação Continuada.

Areia, M. Laranjeira R. de; Rocha, M. A. 1985. O ensino da antropologia. In: Cem anos de Antropologia em Coimbra, 1885-1985. Coimbra, Museu e Laboratório Antropológico: 13-60.

Areia, M. Laranjeira R. de; Rocha, M. A.; Miranda, M. A. 1991. O Museu e Laboratório Antropológico da Universidade de Coimbra. In: Universidade(s). História. Memória. Perspectivas. Actas Congresso "História da Universidade" (no $7^{\circ}$ Centenário da sua Fundação, 1990). Coimbra, Comissāo Organizadora do Congresso "História da Universidade", 2: 87-106.

Armelagos, G. 1997. Paleopathology. In: Spencer, F. (ed.). History of Plysical Anthropology an Encyclopedia. London, Garland Publishing, Inc. : 790-796. Aufderheide, A.; Rodríguez-Martin, C. 1998. The Cambridge Encyclopedia of Human Paleopathology. Cambridge, Cambridge University Press.

Baron, H.; Hummel, S.; Herrmann, B. 1996. Mycobacterium tuberculosis complex DNA in ancient human bones. Joumal of Archaeological Science, 23 (5): 667-671. 
Buisktra, J.; Cook, D. C. 1980. Palaeopathology: an American account. Anmual Review of Ant/hropology, 9: 433-470.

Buikstra, J.; Cook, D. 1992. Paleopatologia. In: Araújo, A.; Ferreira, L. (ed.). Paleopatologia. Paleoepidemiologia. Estudos multidisciplinares. Rio de Janeiro, Escola Nacional de Saúde Pública, Fundação Oswaldo Cruz Panorama: 41-86.

Buikstra, J.; Ubelaker, D. (ed.) 1994. Standards for Data Collection from Human Skeletal Remains. Arkansas Archeological Survey Research Series Number 44. Fayetteville, Arkansas, Arkansas Archaeological Survey.

Campillo, D. 1993. Paleopatología. Los Primeros Vestígios de la Enfermedad (Primera Part). Vol. 4. Barcelona, Fundación Ulriach 1838.

Cardoso, H. 2000. Dimorfismo sexual na estatura, dimensöes e proporçōes dos ossos longos dos membros : o caso de uma amostra portuguesa dos séculos $X I X-X X$. Tese de Mestrado em Evolução Humana, Departamento de Antropologia, Universidade de Coimbra.

Cockburn, E. 1994. The Paleopathology Association: Mortui viventes docent. Eres (Arqueologia), 5(1): 135-147.

Cockburn, E. 1997. An introduction to paleopathology. $I n$ : Elerick, D. (compil.). Human Paleopathology and Related subjects. An International Bibliography. San Diego, San Diego Museum of Man: xv-xvi.

Cockburn, E. 2000. Saul Jarcho's Contribution to the History of Paleopathology. Paleopathology Newsletter, 112: 4-8.

Compre rendu de la neurième session du Congrès International d'Anthropologie et d'Archéologie préhistorique (Lisboa,1880). Lisbonne, Typographie de l'Académie Royale des Sciences, 1884.

Concise Colour Medical Dictionary 1998. Oxford, Oxford University Press.

Cunha, A. Xavier 1982. Contribution à l'histoire de l'Anthropologie Physique au Portugal. Contribuiçōes para o Estudo da Antropologia Portuguesa, 11(1): 1-56.

Cunha, A. Xavier; Neto, M. A. 1953. Características da população da época visigótica de Silveirona (Estremoz). II - Características cranianas. Contribui̧̧óes para o Estudo da Antropologia Portuguesa, 5 (5): 239-309.

Cunha, A. Xavier; Neto, M. A. 1955. Características da população da época visigótica de Silveirona (Estremoz). III- Esqueleto do tronco e dos membros. Contribuições para o Estudo da Antropologia Portugnesa, 6 (1): 5-64.

Cunha, E. 1993. Evolution de la maladie hyperostique à Coimbra de l'époque médiévale à la fin du XIXe siècle. Bulletins et Mémoires de la Société d'Anthropologie de Paris, 5: 313-320. 
Cunha, E. 1994. Paleobiologia das populaçōes medievais portuguesas - os casos de Fão e S. João da Almedina. Tese de doutoramento em Antropologia Biológica, Departamento de Antropologia, Universidade de Coimbra.

Cunha, E. 1995. Testing identification records: evidence from the Coimbra Identified Skeletal Collections (nineteenth and 20 centuries). In: Saunders, S. R.; Herring, A. (ed.) Grave Reflections: portraying the past through cemetery studies. Toronto, Canadian Scholars' Press: 179-198.

Cunha, E.; Gomes, P. 1994. As linhas de Harris na Colecção de Esqueletos Identificados do Departamento de Antropologia da Universidade de Coimbra. Acta Radiológica Portuguesa, 6 (24): 31-36.

Cunha, E.; Umbelino, C. 1995. What bones can tell about labour and occupation: the analysis of skeletal markers of occupation stress in the Identified Skeletal Collection of the Anthropological Museum of the University of Coimbra (preliminary results). Antropologia Porfuguesa, 13: 47-66.

Diário da República 1999. Decreto-lei n²70/99. I-A série, 15 de Julho, $\mathrm{N}^{\circ} 163$ : $4412-4416$.

Drancourt, M.; Aboudharam, G.; Signoli, M.; Dutour, O.; Raoult, D. 1998. Detection of 400-year-old Yersinia pestis DNA in human dental pulp: an approach to the diagnosis of ancient septicemia. Proceedings of the National Academy of Sciences, 95 (21): 12637-12640.

Duarte, C. 1993. Analysis of wear and pathological conditions in human teeth from the Neolithic site of Grutas Artificiais do Tojal de Vila Chã, Carenque (Estremadura, Portugal). Unpublished Master of Arts thesis, Faculty of Graduate Studies and Research, Department of Anthropology, University of Alberta.

Duarte, C.; Maurício, J.; Pettit, P.; Souto, P.; Trinkaus, E.; van der Pllicht, H.; Zilhão, J. 1999. The early Upper Paleolithic human skeleton from the Abrigo do Lagar Velho (Portugal) and modern human emergence in Iberia. Proceedings of the National Acadeny of Sciences, 96: 7604-7609.

Elerick, D. (compil.) 1997. Human Paleopathology and Related subjects. An International Bibliography. San Diego, San Diego Museum of Man.

Ferreira, F. E. R. 1983. Escavações do ossário de S. Vicente de Fora - seu relacionamento com a história de Lisboa. Revista Municipal Lisboa. 44(4): 5-36. Ferreira, F. E. R. 1995. O Cemitério dos Cruzados de São Vicente de Fora. Montmentos, 2: 8-13.

Gernaey, A.; Minnikin, D.; Copley, M.; Ahmed, A.; Chamberlain, A. 1998. Correlation of mycolic acid detection with the incidence of tuberculosis in an 
archaeological population. [Resumol Revista de Portuguesa de Pneumologia, 4(3): 329.

Gernaey, A.; Minnikin, D.; Nolan, J.; Chamberlain, A, 1999. Correlation of the occurrence of mycolic acids with tuberculosis in an archaeological population. In: Pálfi, G.; Dutour, O.; Deák, J.; Hutús, I. (ed.). Tuberculosis: past and present. Budapest-Szeged, Golden Book - TB Foundation: 275-283.

Higuchi, R.; Bowman, B.; Freiberger, M.; Ryder, O.; Wison, A. 1984. DNA sequences from the quagga, an exlinct member of the horse family. Nature, 312: 282-284.

Júnior, A. S. 1947. Exame anátomo-patológico das peças ósseas n. ${ }^{\circ} 80,97,90$. In: Correia, A. M.; Teixeira, C. 1949. A jazida pré-histórica de Eira Pedrinha. Lisboa, Serviços Geológicos de Porıgal: 39-40.

Lessa, A.; Souza, S. 2001. Convívio e Conflito - história cotidiana da vida paleolítica. Inteligência, ano III (12). URL: http://www.insightnet.com.br/ inteligencia / Num 12/m 0112.htm.

Lopes, C. 1997. Silveirona revisitada: nova análise antropológica quatro décadas depois. Relatório de estágio realizado na área de Ciências Humanas, Departamento de Antropologia, Faculdade de Ciências e Tecnologia da Universidade de Coimbra.

Lopes, C.; Cunha, E. 2000). Silveirona revisited: a new anthropological analysis of a Visigothic population. In: Caro Dobon, L. et al. (ed.). Tendencias actuales de investigacion en la Anropologia Fisica Espanola. Leon, Universidad de Leon: 125-130.

Lovell, N. 2000. Paleopathology description and diagnosis. $m$ : Katzenberg, M. A.; Saunders, S. (ed.). Biological Anthropology of the Human Skeleton. New York, Wiley-Liss, Inc. 8: 217-248.

Lubell, D.; Jackes, M.; Schwarcz, H.; Knyf, M.; Meiklejohn, C. 1994. The Mesolithic-Neolithic transition in Portugal: isotopic and dental evidence of diet. Jommal of Archaeological Sciences, 21(2): 201-216.

Lubell, D.; Jackes, M. 1997. Portugal. In: Spencer, F. (ed.) History of Physical Anthropology an Encyclopedia. London, Garland Publishing, Inc.: 834-835. Manchester, K. 1983. The archaeology of disease. Bradford, University of Bradford.

Mendes, J. C.; Oliveira, J. C. 1990. A arqueologia, a biountropologia e a paleopatologia. A propósito do espólio ósseo de Mértola. Arquivo de Anatomia e Antropologia, 41: 205-209.

Merbs, C. 1997. The Multidisciplinary Nature of Paleopathology. Human 
Paleopathology and Related subjects. An Intemational Bibliography. San Diego, San Diego Museum of Man: xix-xx.

Miller, E.; Ragsdale, B.; Ortner, D. 1996. Accuracy in dry bone diagnosis: a comment on palaeopathological methods. Intemational Joumal of Osteoarchaeology, 6 (3): 221-229.

Monteiro, H.; Tavares, A. 1928. Sur l'occipitalization de l'atlas chez les portugais. Annales d'Anatomie Panhologique et d'Anatomie Nomale MédicoChirmrgicale, 5 (6): 1-4.

Olivier, G.; Almeida, M. E. C. 1972. Forme du crâne et mortalité differentielle par tuberculose. L' Anthropologie, 76 (5-6): 471-499.

Ortner, D. 1991. Theoretical and methodological issues in paleopathology. In: Ortner, D. J.; Aufderheide, A. C. (ed.). Haman Paleopathology. Curremt Syntheses and Future Options. Washington and London, Smithsonian Institute Press: 5-11.

Ortner, D.; Putschar, W. 1981. Identification of pathological conditions in Human Skeletal remains. Smithsonitu Contribution to Anthropology, 28.

Päübo, S.; Gifford, J.; Wilson, A. 1988. Mitochondrial sequences from a 7000 year old brain. Nucleic Acids Research, 16: 9775-9787.

Pfeiffer, S. 1991. Is paleopathology a relevant predictor of contemporary health patterns? In: Ortner, D. J.; Aufderheide, A. C. (ed.). Human Paleopathology. Current Syntheses and Future Options. Washington and London, Smithsonian Institute Press: 12-17.

Powell, M. L. 2000. Editorial. Paleopathology Newsletter; 112:1.

Rafi, A.; Spigelman, M.; Stanford, J.; Lemma, E.; Donoghue, H.; Zias, J. 1994. DNA of Mycobacteritum leprae detected by PCR in ancient bone. Intemational Joumal of Osteoarchacology, 4 (4): 287-290.

Roberts, C.; Manchester, K. 1995. The archaeology of disease. Ithaca, New York, Cornell University Press.

Rocha, M. A. 1978. Dents permanentes de la Grotte de Lapa do Suão, Portugal. Contribuições para o Estudo da Antropologia Portuguesa, 10(2): 87-101.

Rocha, M. A. 1995. Les collections ostéologiques humaines identifiées du Musée Anthropologique de l' Université de Coimbra. Antropologia Portuguesa, 13: 7-38.

Rogers, J.; Waldron, T. 1995. A field guide to joint disease in Archaeology. West Sussex, John Wiley \& Sons.

Rogers, J.; Watt, I.; Dieppe, P. 1990. Comparison of visual and radiographic defects of bony changes at the knee joint. British Medical Joumal, 300: 367-368. 
Salo, W.; Aufderheide, A.; Buikstra, J.; Holcomb, T. 1994. Identification of Mycobacterium tuberculosis DNA in a pre-Columbian Peruvian mummy. Proceedings of the National Academy of Sciences, 91 (6): 2091-2096.

Santos, A. L. 2000. A Skeletal Picture of Tuberculosis. Macroscopic, radiological, biomolecular; and historical evidence from the Coimbra Idemified Skeletal Collection. Tese de Doutoramento em Antropologia Biológica, Departamento de Antropologia, Universidade de Coimbra.

Santos, A. L.; Cunha, E. 2001. A severe myeloma which was not recorded as the cause of death of a male individual. [Resumo] In: Powell, M. L. (ed.). Papers on Paleopathology Presented at the twenty eighth Annual Meeting of the Paleopathology Association, Kansas City, Missouri, 27-28 March: 16.

Santos, A.L.; Roberts, C. 2001. A picture of tuberculosis in young Portuguese people in the earlier 20th century: a multidisciplinary study of the skeletal and historical evidence. American Joumal of Physical Anthropology, 115 (1): 38-49.

Schultz, M. 1999. The role of tuberculosis in infancy and childhood in prehistoric and historic populations. In: Pálfi, G.; Dutour, O.; Deák, J.; Hutás, I. (ed.). Tuberculosis: past and present. Budapest-Szeged, Golden Book - TB Foundation: $501-507$.

Schultz, M. 2001. The President's page. Paleopathology Newsletter; 115: 2-3.

Serra, J.; Albuquerque, R.; Neto, M. A. 1952. Características da população da época visigótica de Silveirona (Estremoz). I - Estatura e robustez dos ossos longos. Contribuições para o Estudo da Antropologia Portuguesa, 5 (4): 201-233.

Spencer, F. (ed.) 1997. History of Physical Anthropology an Encyclopedia. London, Garland Publishing.

Spigelman, M.; Lemma, E. 1993. The use of PCR to detect Mycobacteritum tuberculosis in Ancient Skeletons. International Journal of Osteoarcheology, 3: 137-143.

Steinbock, R. T. 1976. Paleopathological Diagnosis and Interpretation: Bone Diseases in Ancient Human Populations. Springfield, Illinois, Charles C. Thomas.

Sueiro, M. B. 1923. Anotações anatómicas. II - Algumas considerações sobre a apófise supra-epitroclear. Arquivo de Anatomia e Antropologia, 8: 241-276.

Sueiro, M. B. 1924/25. O buraco oleocraniano. Arquivo de Anatomia e Antropologia, 9: 95-216.

Sueiro, M. B. 1926. Nota sôbre a frequência de algumas variações do ráquis humano. Arquivo de Anatomia e Antropologia, 10: 237-250. 
Sueiro, M. B. 1931. Note sur la basalité des sacrums préhistoriques. Arquivo de Anatomiat e Antropologia, 13: 586-589.

Sueiro, M. B. 1932. Nota sôbre um sacro humano mesolítico. Arquivo de Anctomia e Antropologia, 14: 13-16.

Sueiro, M. B. 1933/34. Variações múltiplas dum ráquis humano de adulto. Arquivo de Anatsmia e Antropologia, 16: 355-369.

Sueiro, M. B.; Frazão, J. 1957/9. Lesões dentárias no homen do mesolítico Português. Arquivo de Anatomia e Antropologia, 30: 197-209.

Tamagnini, E. 1947. L'Anthropologie au Portugal. (Conferência efectuada na sede do Royal Anthropological Institute of Great Britain and Ireland em 18 de Abril de 1946). Coimbra, Tipografia Atlântida.

Tamagnini, E.; Serra, J. A. 1942. Subsídios para a história da antropologia portuguesa actividade cientifica portuguesa. Memória apresentada ao Congresso de Actividade Científica Portuguesa (Coimbra 1940). Coimbra.

Torre de Palma, Portugal hitp://www.louisville.edu/ aoclar(01/torredp /Torre_dp. htm [Acedido em 200)] ].

Tyson, R. 1997. Acknowledgements. In: Elerick, D. (compil.). Human Paleopathology and Related subjects. An International Bibliography. San Diego, San Diego Museum of Man: xi-xiii.

Ubelaker, D. 1982. The development of American paleopathology. In: Spencer, F. (ed.). A History of American Physician Antiropology 1930-1980. New York, Academic Press: 337-356.

Ubelaker, D. 1998. Ancient disease in anthropological context. $m$ : Greenblatt, C. (ed.). Diggings for parhogens. Center for the study of emerging diseases, Jerusalem. Rehovot, Philadelphia, Balaban Publishers 10: 175-199.

Wakely, J.; Manchester, K.; Roberts, C. 1989. Scanning electron microscope study of normal vertebrite and ribs from early medieval human skeletons. Journal of Archaeological Science, 16: 627-642.

Waldron, T. 1994. Coumting the dead: the epidemiology of skeletal populations. Chichester, John Wiley \& Sons.

Wells, C. 1964. Ossos, corpos e doenças. Lisboa, Editorial Verbo. 